\title{
МОРФОЛОГИЧЕСКИЕ ПРЕДИКТОРЫ СТОМАТОЛОГИЧЕСКОЙ ЗАБОЛЕВАЕМОСТИ У ДЕТЕЙ С ВРОЖДЕННОЙ ПСИХОНЕВРОЛОГИЧЕСКОЙ СИМПТОМАТИКОЙ
}

\author{
(C) Гайворонский И.В. ${ }^{1,7}$, Гуленко О.В. ${ }^{2}$, Гайворонская Т.В. ${ }^{2}$, Байбаков С.Е. ${ }^{3}$, Проходная В.А. ${ }^{6}$, \\ Попков В.Л. ${ }^{4}$, Рисованная О.Н. ${ }^{5}$, Гайворонская М.Г. ${ }^{7}$
}

\begin{abstract}
${ }^{1}$ Кафедра нормальной анатомии Военно-медицинской академии им. С. М. Кирова, Санкт-Петербург; ${ }^{2}$ кафедра хирургической стоматологии и челюстно-лицевой хирургии, ${ }^{3}$ кафедра нормальной анатомии, ${ }^{4}$ кафедра ортопедической стоматологии, ${ }^{5}$ кафедра стоматологии ФПК и ППС Кубанского государственного медицинского университета, Краснодар; ${ }^{6}$ кафедра стоматологии № 1 с курсом подготовки обучающихся стоматологического факультета к аккредитации Ростовского государственного медицинского университета, Ростов-на-Дону; ${ }^{7}$ кафедра морфологии СанктПетербургского государственного университета, Санкт-Петербург
\end{abstract} E-mail: solnushko12@mail.ru

\begin{abstract}
Исследование проведено с целью выявления распространенности пороков развития челюстно-лицевой области и органов полости рта у детей с врожденной психоневрологической патологией и определения их предиктивных свойств в формировании приобретенных стоматологических заболеваний. Объектом исследования явились 277 детей с психоневрологической патологией и 260 детей без коморбидной патологии. Установлено, что у детей с психоневрологической патологией наблюдается высокий процент врожденной патологии челюстно-лицевой области и полости рта в сравнении с контрольной группой. Выявленные орофациальные аномалии можно квалифицировать как врожденные морфологические предикторы стоматологических заболеваний, так как они являются известными и доказанными факторами риска развития болезней твердых тканей зубов, пародонта, хейлитов, стоматитов и т.д.
\end{abstract}

Ключевые слова: дети, психоневрологическая патология, орофациальные аномалии, стоматологическая заболеваемость.

\section{MORPHOLOGICAL PREDICATORS OF DENTAL MORBIDITY IN CHILDREN WITH CONGENITAL PSYCHONEUROLOGICAL PATHOLOGY}

Gayvoronskiy I.V. ${ }^{1,7}$, Gulenko O.V. ${ }^{2}$, Gayvoronskaya T.V. ${ }^{2}$, Baybakov S.E. ${ }^{3}$, Prokhodnaya V.A. ${ }^{6}$, Popkov V.L. ${ }^{4}$, Risovannaya O.N. ${ }^{5}$, Gayvoronskaya M.G.

${ }^{1}$ Department of Normal Anatomy of S.M. Kirov Military Medical Academy, St. Petersburg;

${ }^{2}$ Department of Surgical Dentistry and Maxillofacial Surgery, ${ }^{3}$ Department of Normal Anatomy,

${ }^{4}$ Department of Prosthetic Dentistry, ${ }^{5}$ Dentistry Department of Postgraduate Faculty

of Kuban State Medical University, Krasnodar; ${ }^{6}$ Department of Stomatology $N 1$ with the Course of Dental Students'

Preparation for Accreditation of Rostov State Medical University, Rostov-on-Don;

${ }^{7}$ Department of morphology of St. Petersburg State University, St. Petersburg

The study was conducted to identify the prevalence of malformations of the maxillofacial area and oral organs in children with congenital neuropsychiatric disorders and to determine their predictive properties in the formation of acquired dental diseases. The object of the study involved 277 children with neuropsychiatric pathology and 260 children without comorbid pathology. It was established that children with neuropsychiatric pathology had a high percentage of congenital pathology of the maxillofacial area and oral cavity in comparison with the control group. The identified orofacial anomalies can be classified as congenital morphological predictors of dental diseases, as they are well-known and proven risk factors for developing hard dental tissue diseases, periodontal disease, cheilitis, stomatitis, etc.

Keywords: children, neuropsychiatric pathology, orofacial anomalies, dental morbidity.

Орофациальные аномалии у детей - частые спутники врожденной психоневрологической патологии (ПНП), в основе которой лежат многочисленные нарушения развития структур головного мозга с соответствующими когнитивными, коммуникативными и судорожными расстройствами [2]. Несмотря на развитие пренатальной диагностики, уровень психоневрологической заболеваемости не снижается, в том числе из-за тенденциозного увеличения материнского возраста [1]. По данным разных авторов, у детей с ПНП встречаются изолированные и сочетанные пато- логии сердечно-сосудистой, дыхательной и эндокринной систем, органа зрения, слуха, врожденный вывих бедра $[1,2,4,11]$. Опорнодвигательный аппарат характеризуется деформациями стопы, нарушениями осанки, диспропорциями телосложения, функциональной недостаточностью брюшных мышц, парезами, кривошеей $[1,2,4,11]$.

По мнению ряда авторов, такие дети имеют более высокий риск развития стоматологических проблем, которые могут дополнительно негативно влиять на их благополучие и качество жизни 
$[9,12]$. В доступной литературе упоминается о том, что стоматологические аномалии как временных, так и постоянных зубов имеют значительную распространенность. Так, у пациентов с синдромом Дауна зубные аномалии встречаются с частотой, в пять раз превышающей этот показатель в здоровой популяции $[5,8,9,10,13]$. Во временном прикусе наиболее часто наблюдается первичная адентия боковых резцов, в то время как в постоянном прикусе наиболее часто подвержены первичной адентии третьи моляры, вторые премоляры и боковые резцы в указанной последовательности [9]. Согласно некоторым авторам, наиболее распространенными аномалиями, связанными с аутизмом, умственной отсталостью и синдромом Дауна, являются вариации числа зубов и их морфологии: часто наблюдаются боковые резцы конической формы, резцы «лопатообразной» формы и тауродонтизм $[5,8,9,10,12$, 13]. По мнению тех же авторов, у таких детей прорезывание зубов задерживается либо происходит в необычном порядке.

Таким образом, скрининг врожденных предикторов высокой стоматологической заболеваемости пациентов с психоневрологической патологией должен составлять важную часть их первоначального обследования у врача-стоматолога $[6,7]$.

Цель исследования: выявить распространенность и систематизировать пороки развития челюстно-лицевой области и органов полости рта у детей с врожденной психоневрологической патологией для определения их предиктивных свойств в развитии стоматологических заболеваний.

\section{МАТЕРИАЛЫ И МЕТОДЫ ИССЛЕДОВАНИЯ}

В детском отделении стоматологической поликлиники КубГМУ проведено обследование 277 детей 7-17 лет с ПНП (детский церебральный паралич (ДЦП) - 47 детей, аутизм - 45 детей, синдром Дауна - 30 детей, умственная отсталость (УО) - 155 детей). Данные пациенты составили основную группу. Использовались основные методы обследования (осмотр, опрос, пальпация, инструментальное обследование) и дополнительные (рентгенологическое обследование (прицельная рентгенография, ортопантомография (ОПТГ), спиральная компьютерная томография (КТ), телерентгенография (ТРГ)). Контрольную группу исследования составили 260 соматически здоровых детей. Родители или опекуны детей документально подтвердили согласие на участие в исследовании.

Для сравнения функционально-морфологических характеристик здоровья ЧЛО детей с ПНП с контрольной группой детей без коморбидной патологии была использована количественная модель исследования «случай-контроль». Сравнительный анализ параметра частоты проводился с использованием критерия $\chi^{2}$, при этом статистически значимыми считались различия в относительных долях при $\mathrm{p}<0,05$.

\section{РЕЗУЛЬТАТЫ ИССЛЕДОВАНИЯ И ИХ ОБСУЖДЕНИЕ}

Клинико-рентгенологическое обследование выявило у детей с ПНП высокий процент врожденной патологии (скелетные аномалии ЧЛО, аномалии мягких тканей, зубов и функциональные аномалии органов полости рта) в сравнении с контрольной группой (таблицы 1,2 ). Скелетные аномалии в подавляющем большинстве случаев были представлены нарушениями окклюзии $(94,5 \%, \mathrm{p}<0,05)$, что в 1,8 раза превышает этот показатель в группе контроля. При этом следует отметить, что высокое аркообразное твердое небо и расщелина неба присутствовали лишь в основной группе, а количество случаев с деформациями черепа в основной группе значительно преобладали над аналогичным показателем контрольной группы (в 58,7 раза) (рис. 1). Наличие врожденных деформаций черепа может быть этиологической составляющей последующего формирования нарушений прикуса, а также способствовать развитию миофункциональных проблем, генерирующих дисбаланс в стоматогнатической системе детей с ПНП.

Из аномалий мягких тканей ЧЛО в детей с ПНП заслуживают внимания особенности строения языка, проявляющиеся в макроглоссии и складчатости языка, что в 35,6 раза превышает показатели макроглоссии, выявленные у детей без коморбидной патологии. Макроглоссия, практически единодушно, многими авторами признается как ведущий предиктор в развитии скелетных аномалий прикуса, связанных с неконтролируемым ростом нижней челюсти. Микростомия в $18,6 \%$ и $16,7 \%$ случаев фигурировала у детей с синдромом Дауна и УО соответственно. Факт наличия микростомии значительно осложняет стоматологическое лечение и диагностику, а также может оказывать существенное влияние на недоразвитие челюстных костей. Следует отметить также нарушение позиционирования языка в полости рта и низкий тонус круговой мышцы рта, языка, жевательных мышц, которые соответственно в 1,9 и 2,1 раза чаще встречаются в основной группе по сравнению с контрольной. Данный факт в полной мере объясняет высокую частоту ортодонтических нарушений, хейлитов, явлений дроулинга ротовой жидкости и высокой заболеваемости пародонта и твердых тканей зубов. 
Структура орофациальных аномалий у детей основной и контрольной групп

(относительные доли распространенности в \%)

\begin{tabular}{|c|c|c|}
\hline $\begin{array}{c}\text { Вид } \\
\text { нарушения ЧЛО }\end{array}$ & $\begin{array}{l}\text { Основная группа } \\
\text { (дети с ПНП) }\end{array}$ & $\begin{array}{c}\text { Контрольная } \\
\text { группа }\end{array}$ \\
\hline \multicolumn{3}{|l|}{ Скелетные аномалии } \\
\hline Деформации черепа & 44,65 & 0,76 \\
\hline Высокое аркообразное твердое небо & 19,31 & - \\
\hline Расщелина неба & 6,9 & - \\
\hline Нарушения окклюзии & 94,5 & 52,4 \\
\hline \multicolumn{3}{|l|}{ Аномалии мягких тканей } \\
\hline Микростомия & 8,82 & - \\
\hline Аномалии строения языка (макроглоссия, складчатость) & 42,8 & 1,2 \\
\hline Нарушение позиционирования языка в полости рта & 76,7 & 38,7 \\
\hline Низкий тонус круговой мышцы рта, языка, жевательных мышц & 91,0 & 41,5 \\
\hline \multicolumn{3}{|l|}{ Аномалии зубов } \\
\hline $\begin{array}{l}\text { Аномалии анатомии зубов (микродонтия, тауродонтизм, конические } \\
\text { зубы и пр.) }\end{array}$ & 50,5 & 9,7 \\
\hline Нарушение сроков прорезывания временных и постоянных зубов & 52,3 & 13,8 \\
\hline Первичная адентия & 44,4 & 25,3 \\
\hline Аномалии комплектности зубов & 63,9 & 26,5 \\
\hline \multicolumn{3}{|c|}{ Функциональные аномалии органов полости рта } \\
\hline Дроулинг слюны & 69,5 & - \\
\hline Нарушения ротового дыхания & 91,1 & 46,9 \\
\hline Бруксизм & 50,4 & - \\
\hline Дисфункция ВНЧС & 79,7 & 22,7 \\
\hline
\end{tabular}

Таблица 2

Частота встречаемости орофациальных аномалий у детей с разными видами ПНП внутри контрольной группы (относительные доли распространенности в \%)

\begin{tabular}{|c|c|c|c|c|}
\hline \multirow[t]{2}{*}{ Вид нарушения ЧЛО } & \multicolumn{4}{|c|}{ Вид ПНП } \\
\hline & ДЦП & Аутизм & Синдром Дауна & $\mathrm{yO}$ \\
\hline \multicolumn{5}{|l|}{ Скелетные аномалии } \\
\hline Деформации черепа & 53,5 & 17,4 & 46,3 & 61,4 \\
\hline Высокое аркообразное твердое небо & 12,3 & - & 56,7 & 17,9 \\
\hline Расщелина неба & 7,3 & 3,9 & 10,1 & 6,3 \\
\hline Нарушения окклюзии & 95,4 & 86,7 & 98,3 & 97,6 \\
\hline \multicolumn{5}{|l|}{ Аномалии мягких тканей } \\
\hline Микростомия & - & - & 18,6 & 16,7 \\
\hline Аномалии строения языка (макроглоссия, складчатость) & 47,9 & 31,4 & 56,5 & 35,4 \\
\hline Нарушение позиционирования языка в полости рта & 99,2 & 52,3 & 78,4 & 76,9 \\
\hline Низкий тонус круговой мышцы рта, языка, жевательных мышц & 98,9 & 76,5 & 97,5 & 91,4 \\
\hline \multicolumn{5}{|l|}{ Аномалии зубов } \\
\hline $\begin{array}{l}\text { Аномалии анатомии зубов (микродонтия, тауродонтизм, } \\
\text { конические зубы и пр.) }\end{array}$ & 8,7 & 58,9 & 90,7 & 43,6 \\
\hline $\begin{array}{l}\text { Нарушение сроков прорезывания временных и постоянных } \\
\text { зубов }\end{array}$ & 71,3 & 53,2 & 34,8 & 37,3 \\
\hline Первичная адентия & 13,9 & 21,5 & 24,2 & 18,3 \\
\hline Аномалии комплектности зубов & 9,6 & 11,2 & 15,6 & 19,5 \\
\hline \multicolumn{5}{|c|}{ Функциональные аномалии органов полости рта } \\
\hline Дроулинг слюны & 68,9 & 43,4 & 76,8 & 89,2 \\
\hline Нарушения ротового дыхания & 94,4 & 76,8 & 96,7 & 96,5 \\
\hline Бруксизм & 89,4 & 23,5 & 32,3 & 56,6 \\
\hline Дисфункция ВНЧС & 75,7 & 54,9 & 98,3 & 89,9 \\
\hline
\end{tabular}




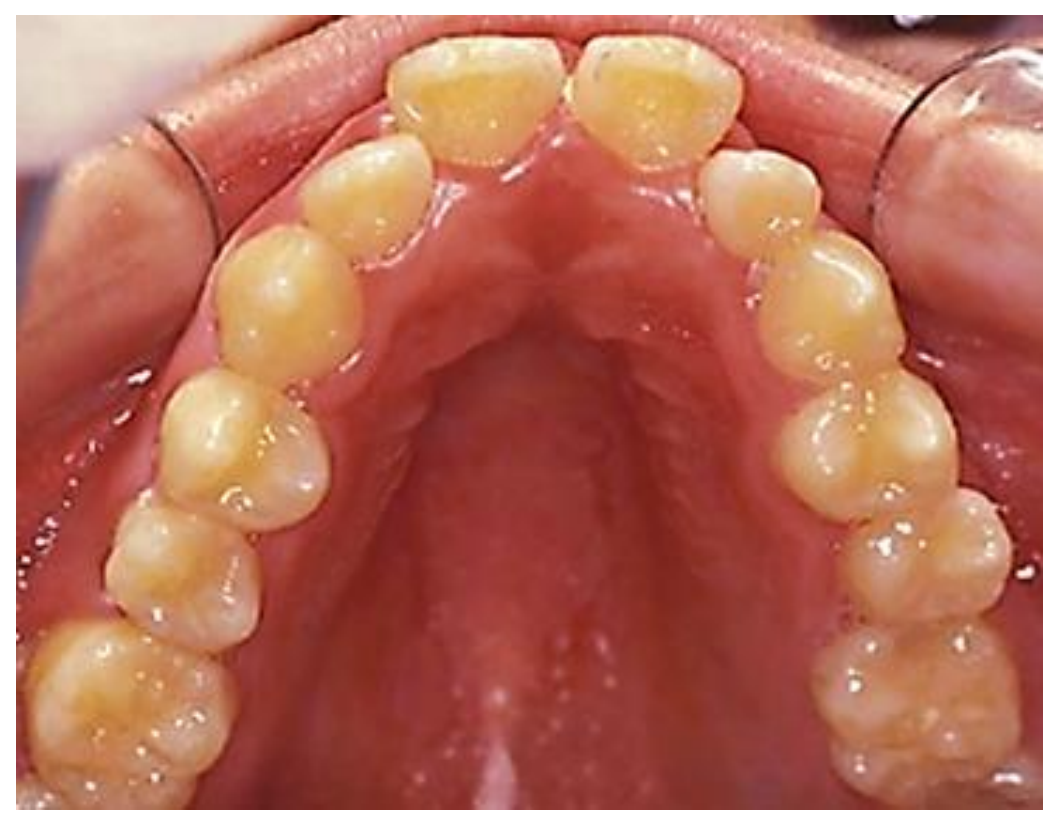

Рис. 1. Пациент К., 14 лет. Аутизм. Аркообразное небо, сужение верхней челюсти.

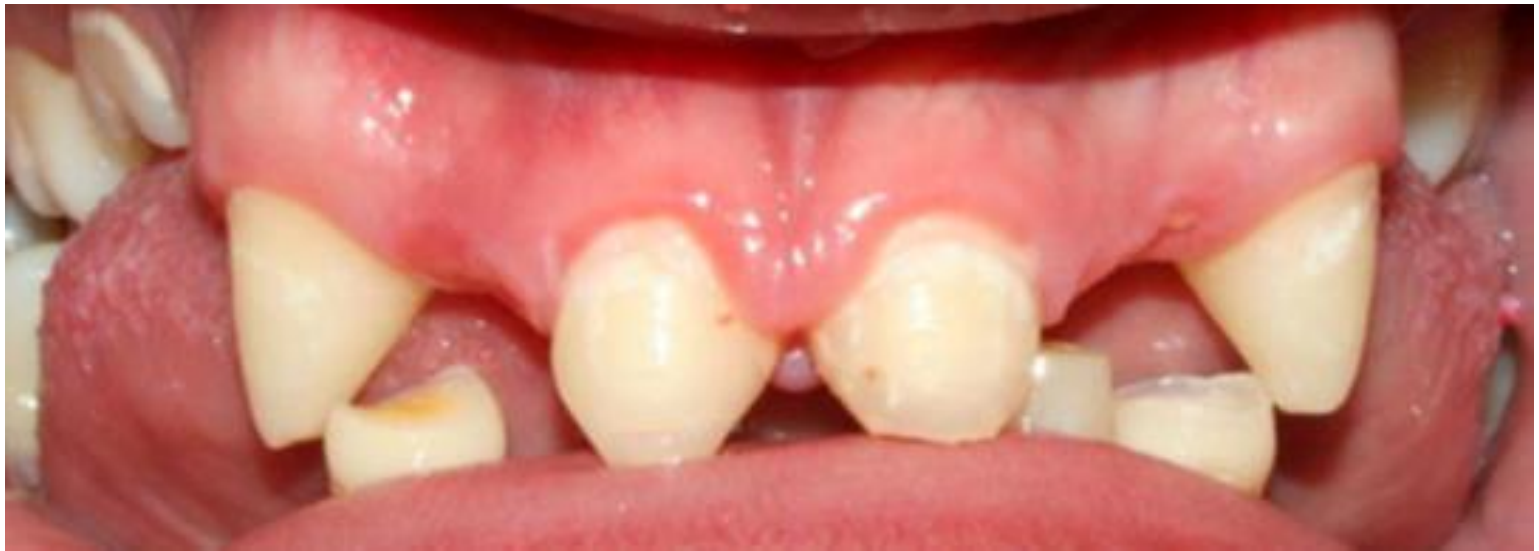

Рис. 2. Пациент О., 8 лет. Синдром Дауна. Аномалия формы центральных резцов («конические зубы»), первичная адентия временных и постоянных боковых резцов, макроглоссия, патология окклюзии.

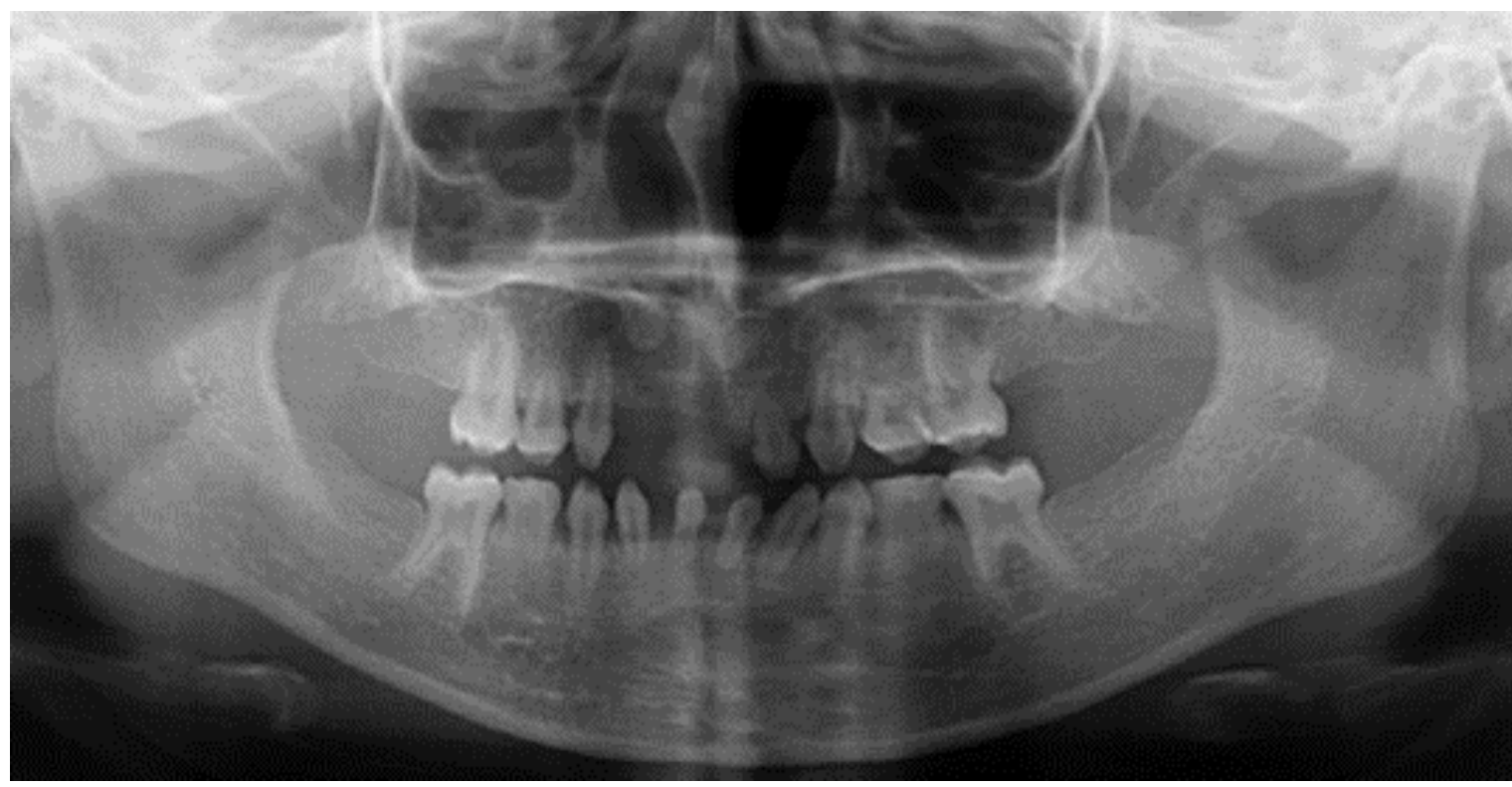

Рис. 3. Пациент И., 10 лет. Умственная отсталость. Ортопантомограмма демонстрирует состояние полностью сформированного молочного прикуса с отсутствующими центральным и правым боковым резцом верхней челюсти и полным отсутствием зачатков постоянных зубов. 


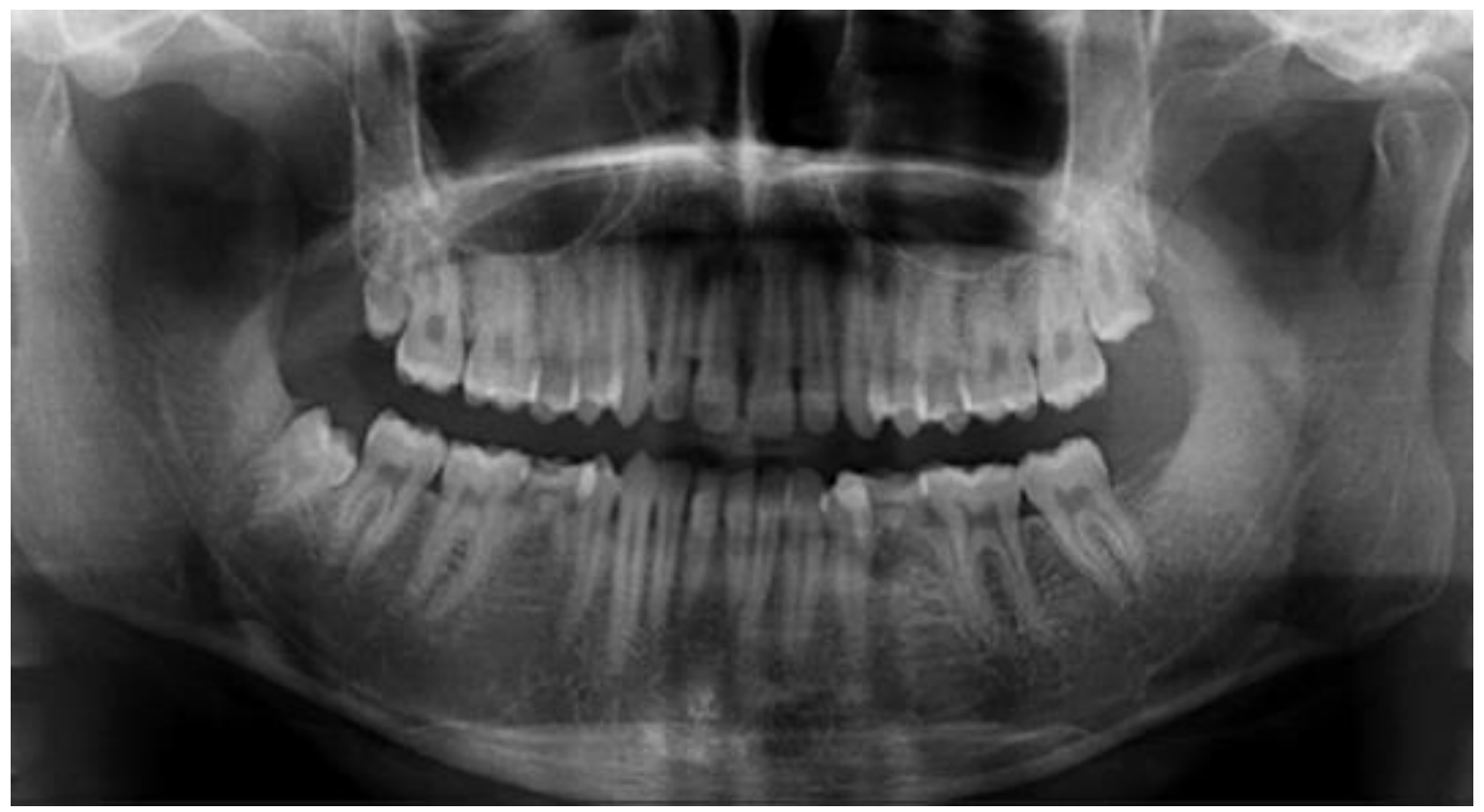

Рис. 4. Пациент О., 15 лет. Детский церебральный паралич. Ортопантомограмма демонстрирует отсутствие зачатков $35,45,38$ зубов.

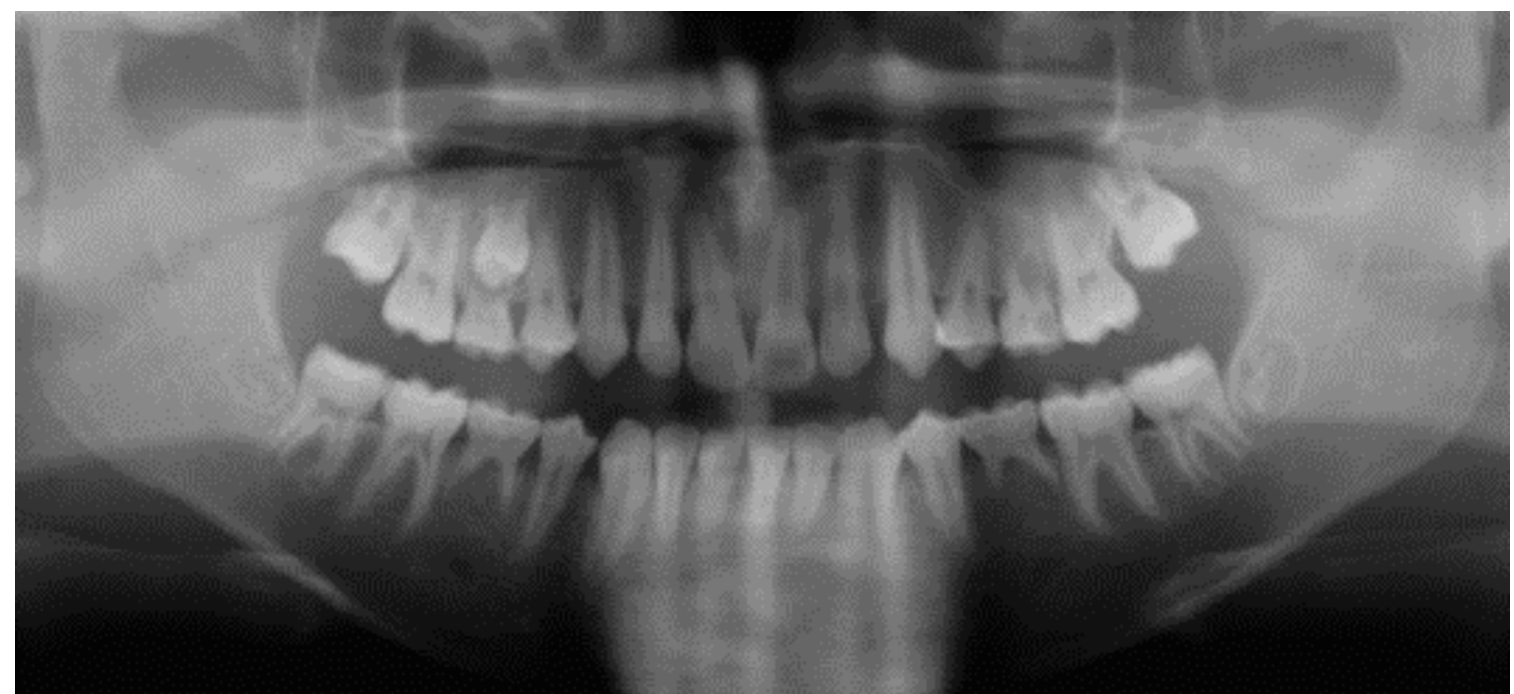

Рис 5. Пациент С., 14 лет. Аутизм. Ортопантомограмма демонстрирует отсутствие зачатков 25, 35, 45 зубов.

Аномалии зубов в сопоставимых значениях были представлены в основной группе нарушениями анатомии (микродонтия, тауродонтизм, конические зубы и пр.), сроков прорезывания временных и постоянных зубов, первичной адентией и нарушениями комплектности зубных рядов. В среднем, частота проявлений всех видов аномалий зубов у детей с ПНП в 2,8 раза превышает данный показатель у детей контрольной группы. Подобные проявления приводят не только к развитию нарушений окклюзии: нарушение анатомии зубов ухудшает их самоочищение, снижает эффективность эндодонтического лечения вследствие аномальных особенностей внутреннего строения зубов, а также ухудшает эстетику улыб- ки, что отрицательно влияет на социализацию данного контингента пациентов.

Функциональные аномалии органов полости рта (нарушения ротового дыхания и дисфункция ВНЧС), являющиеся скорее следствием описанных выше орофациальных аномалий, представлены в обеих группах исследования, однако данные показатели достоверно выше аналогичных в контрольной группе (в 1,9 и 3,5 раза соответственно). Частота бруксизма была наиболее высокой у детей с ДЦП (89,4\%), а дроулинг ротовой жидкости чаще всего выявлялся у детей с УО $(89,2 \%)$, однако средние цифры частоты проявлений данных функциональных расстройств в основной группе составили $50,4 \%$ и $69,5 \%$ соответственно, притом у детей контрольной группы эти нарушения не 
были выявлены. Явления бруксизма способны усугублять ортодонтическую патологию и способствовать формированию миофункциональных нарушений. Дроулинг слюны возникает, повидимому, в раннем постнатальном периоде вследствие дисфункций вегетативной нервной системы, что вполне закономерно для детей с ПНП. Однако усиливать это явление в дальнейшем способны и другие анатомо-функциональные нарушения и аномалии, описанные выше: нарушения акта глотания, снижение функции круговой мышцы рта, нарушения окклюзии, аркообразное небо. Явления дроулинга у детей с ПНП в совокупности с ксеростомией способствуют нарушениям гомеостаза полости рта в целом и являются важнейшим фактором риска развития стоматологической патологии [3].

Анализируя вышесказанное, можно сделать следующие выводы.

Bсе выявленные нарушения могут быть квалифицированы как врожденные орофациальные аномалии развития, обусловленные дисэмбриогенезом в период, общий для формирования нервной трубки и полости рта (5-6 неделя).

Орофациальные аномалии у детей с ПНП по частоте значительно превосходят показатели контрольной группы $(\mathrm{p}<0,05)$, а некоторые из них (деформации черепа, микростомия, бруксизм, дроулинг ротовой жидкости) в принципе не выявлены у здоровых детей.

Выявленные орофациальные аномалии можно квалифицировать как врожденные морфологические предикторы стоматологических заболеваний, так как они являются известными и доказанными факторами риска развития болезней твердых тканей зубов, пародонта, хейлитов, стоматитов и т.д.

Таким образом, систематизация и выявление причинно-следственных связей в развитии приобретенных стоматологических заболеваний у детей с психоневрологической патологией и орофациальными аномалиями может способствовать разработке превентивных и практических стратегий для управления коморбидной патологией (психоневрологические расстройства) в целях снижения стоматологической заболеваемости данного контингента.

\section{КОНФЛИКТ ИНТЕРЕСОВ}

Авторы декларируют отсутствие явных и потенциальных конфликтов интересов, связанных с публикацией настоящей статьи.

\section{ЛИТЕРАТУРА / REFERENCES}

1. Баранов А.А., Альбицкий В.Ю., Иванова А.А., Терлецкая Р.Н., Косова С.A. Тенденции заболеваемо- сти и состояние здоровья детского населения Российской Федерации // Российский педиатрический журнал. - 2012. - № 6. - C. 4-9. [Baranov A.A., Albitsky V.Yu., Ivanova A.A., Terletskaya R.N., Kosova S.A. Trends and the health status of the child population of the Russian Federation. Rossiyskiy pediatricheskiy zhurnal. 2012; (6): 4-9 (in Russ.)].

2. Беликова А.А., Микляева Т.А., Шамшадинова А.Р. Особенности ведения стоматологических пациентов со стойкими нарушениями центральной нервной системы // Бюллетень медицинских интернетконференций. - 2015. - Т. 5, № 10. - С. 1242-1243. [Belikova A.A., Miklyayeva T.A., Shamshadinova A.R. Features of the management of dental patients with persistent disorders of the central nervous system. Byulleten' meditsinskikh internet-konferentsiy. 2015; 5(10): 1242-1243 (in Russ.)].

3. Гуленко О.В., Быков И.М., Гайворонская Т.В. Дроулинг слюны у детей с психоневрологическими расстройствами как фактор риска развития стоматологической патологии // Стоматолог. Минск. 2017. - № 4 (27). - C. 48-53. [Gulenko O.V., Bykov I.M., Gayvoronskaya T.V. Drooling of saliva in children with psychoneurological disorders as a risk factor for the development of dental pathology. Stomatolog. Minsk. 2017; 27(4): 48-53 (in Russ.)].

4. Дониёрова Ф.A. Соматический и неврологический статус детей с аутизмом // Молодой ученый. 2017. - T. 154, № 20. - C. 189-192. [Doniyorova F.A. Somatic and neurological status of children with autism. Molodoy uchenyy. 2017; 154(20): 189-192. (in Russ.)].

5. Кольикина М.С., Кочетова М.С. Некоторые особенности обследования пациента с детским церебральным параличом на ортодонтическом приеме // Бюллетень медицинских интернет-конференций. - 2017. - Т. 7, № 9. - С. 1487-1489. [Kolyshkina M.S., Kochetova M.S. Some features of the examination of a patient with cerebral palsy on orthodontic treatment. Byulleten' meditsinskikh internetkonferentsiy. 2017; 7(9): 1487-1489 (in Russ.)].

6. Лапина Н.В. Показатели качества жизни - как субъективная оценка функционального состояния стоматологических больных с невротическими расстройствами до и после ортопедического лечения // Казанская наука. - 2011. - № 2. - С. 240-243. [Lapina N.V. The qualitative indices of life as subject estimation of functional condition stomatological patients with neurotic disorders before and after orthopedic treatment. Kazanskaya nauka. 2011; (2): 240-243 (in Russ.)].

7. Рустамова Э.В., Лапина Н.В., Сеферян К.Г., Попков В.Л., Ижнина Е.В. Влияние уровня тревожности на качество жизни пациентов с частичным отсутствием зубов и дисфункциональными состояниями ВНЧС на этапах ортопедической реабилитации // Сеченовский вестник. - 2017. - № 3(29). C. 38-43. [Rustamova E.V., Lapina N.V., Seferyan K.G., Popkov V.L., Izhnina E.V. The influence of the level of anxiety on quality of life ofpatients with partial lack of teeth and dysfunctional states of the temporomandibular joint at the stages of orthopedic 
rehabilitation. Sechenovskiy vestnik. 2017; 29(3): 38-43 (in Russ.)].

8. Al Hashmi H., Kowash M., Hassan A., Al Halabi M. Oral Health Status among Children with Cerebral Palsy in Dubai, United Arab Emirates // J Int Soc Prev Community Dent. - 2017. - Vol. 7, Suppl. 3. - P. 149154. - DOI: 10.4103/jispcd.JISPCD_295_17.

9. Ghaith B., Al Halabi M., Kowash M. Dental Implications of Down Syndrome (DS): Review of the Oral and Dental Characteristics // JSM Dent. - 2017. Vol. 5, N 2. - P. 1087.

10. Jan B.M., Jan M.M. Dental health of children with cerebral palsy // Neurosciences (Riyadh). - 2016. Vol. 21, N 4. - P. 314-318. - DOI: 10.17712/nsj.2016.4.20150729.
11. Kawakami M., Liu M., Otsuka T., Wada A., Uchikawa K., Aoki A., Otaka Y. Asymmetric skull deformity in children with cerebral palsy: frequency and correlation with postural abnormalities and deformities // J Rehabil Med. - 2013. - Vol. 45, N 2. - P. 149-153. DOI: 10.2340/16501977-1081.

12. Sixou J.-L., Vernusset N., Daigneau A., Watine D., Marin L. Orofacial therapy in infants with Down syndrome // Dentofacial Anom Orthod. - 2017. - Vol. 20, N 1. - P. 108. - DOI: 10.1051/odfen/2016038.

13. Torales J., Barrios I., González I. Problemáticas de salud bucodental en personas con trastornos mentales. Oral and dental health issues in people with mental disorders // Medwave. - 2017. - Vol. 17, N 8. P. 7045. - DOI: 10.5867/medwave.2017.08.7045.

Поступила в редакцию 11.10.2018 Подписана в печать 20.12.2018 